\title{
Operation Analysis of a Communication-Based DC Micro-Grid Using a Hardware Simulator
}

\author{
Ji-Heon Lee ${ }^{*}$, Hyun-Jun Kim ${ }^{*}$, and Byung-Moon Han ${ }^{\dagger}$ \\ $\dagger^{*}$ Dept. of Electrical Engineering, Myongji University, Yongin, Korea
}

\begin{abstract}
This paper describes the operation analysis results of a communication-based DC micro-grid using a hardware simulator developed in the lab. The developed hardware simulator is composed of distributed generation devices such as wind power, photovoltaic power and fuel cells, and energy storage devices such as super-capacitors and batteries. Whole system monitoring and control was implemented using a personal computer. The power management scheme was implemented in a main controller based on a TMS320F28335 chip. The main controller is connected with the local controller in each of the distributed generator and energy storage devices through the communication link based on a CAN or an IEC61850. The operation analysis results using the developed hardware simulator confirm the ability of the DC micro-grid to supply the electric power to end users.
\end{abstract}

Key words: CAN (Controller Area Network), CCP (CAN Calibration Protocol), DC Micro-grid, DG (Distributed Generation), Energy Storage, IEC61850, MPPT (Maximum Power Point Tracking), PMSG (Permanent Magnet Synchronous Generator), Power Management System, PV (Photovoltaic)

\section{INTRODUCTION}

A micro-grid is a small power grid which is composed of distributed generation and energy storage systems. A microgrid can operate in grid-tied mode or in islanded mode. In the grid-tied mode the micro-grid operates in parallel with the utility grid to exchange power for balancing the supply power with consumed demand. However, when a fault occurs in the utility grid, the micro-grid operates in islanded mode. In the islanded mode the micro-grid has to carry out the power balance by generation reduction or load shedding [1], [2].

Micro-grids can be classified as an AC micro-grid or as a DC micro-grid depending on whether the components are integrated through an AC or DC network. DC micro-grids do not require synchronization, stability, and reactive power compensation. They have low system losses and a low system cost because the power generated by renewable sources can be directly connected to the load through one-stage power conversion [3]-[5].

There are two control methods for the DC micro-grids. One method is an autonomous control without a communication

Manuscript received Sep. 1, 2012; revised Feb. 6, 2013

Recommended for publication by Associate Editor Seung-Ho Song.

${ }^{\dagger}$ Corresponding Author: erichan@mju.ac.kr

Tel: +82-31-335-6563, Fax: +82-31-330-6816, Myongji University

*Dept. of Electrical Engineering, Myongji University, Korea link, in which the converter output voltage is regulated by using droop control. The advantage of this autonomous control is its elimination of the circulating current between connected converters [6]-[9].

However, this method causes frequent transient phenomena to occur in the regulation procedure. In addition, a slow dynamic response and stability degradation are disadvantages. Another method is a direct control with a communication link, in which the generated, stored, and consumed power are measured and transmitted to the main controller in real time [10]-[12]. This method can offer reliable operation if a highspeed communication link is available, which enables fast data transmission between the main controller and the local controller.

The operation of a micro-grid can be analyzed using off-line simulation models with commercially available software [13]. However, only short-term simulation can be carried out due to restrictions in running time. Therefore, it is impossible to use these models for long-term operation analysis. Long-term operation analysis can be carried out with a real-time digital simulator which is composed of specially designed hardware and software [14]. However, hardware-related performance and losses cannot be analyzed in detail.

This paper describes a real-time hardware simulator which can be utilized for the long-term operation analysis of DC 
micro-grids with a reliable communication link [15]. The realtime hardware simulator described in this paper is a lab-based test bed for DC micro-grids. It can be utilized for deriving the engineering data needed for designing actual DC micro-grids and for obtaining the optimal operation scheme.

\section{DC MICRO-GRID STRUCTURE}

Fig. 1 shows the configuration of a DC micro-grid including a communication link and a monitoring system. The DC micro-grid is composed of distributed sources, like wind power, photovoltaic generators and fuel-cell generators; energy storage devices, like batteries and super-capacitors; plus DC loads, and the AC main grid. Its system parameters, control, and converter topology are described in [13]. Each converter is controlled by a local controller designed with a TMS320F28335. All of the data for system control and monitoring are transmitted to or received from the main controller. The main controller has several functions such as power management, system control, and system monitoring. It sends command signal for system control and monitoring to the local controller through a communication link. A CAN (Controller Area Network) was used for the data communication between the grid-tied converter and the energy storage converter. An IEC61850 Ethernet-based communication link was used for the data communication between the main controller and the local controllers for the grid-tied converter and all of the power source converters.

Fig. 2 shows the basic configuration of the communication link. A small-scale CAN is used for data communication between the energy storage converter controller and the gridtied converter controller. The main controller cannot directly send data to or receive data from the local controllers because the local controllers only accept data communication through the CAN, while the main controller accepts data communication through the IEC61850 protocol. As a result, a gateway is required between the local controllers and the main controller. Usually the energy storage system and the grid-tied converter can be installed in the same location for convenience. The local controllers for the grid-tied converter, the battery converter and the super-capacitor converter are linked together through the small-scale CAN, in order to improve the dynamic response and stability through rapid data communication and mode changes.

On the other hand, the distributed power sources are sometimes separately installed in a remote area. The local controllers for these sources are connected to the main controller via a gateway. The communication link between the local controllers and the gateway was implemented through the CCP (Can Calibration Protocol), while the communication link between the gateway and the main controller was implemented through the IEC61850 protocol. As a result, the local controller works like a CCP slave, while the gateway works

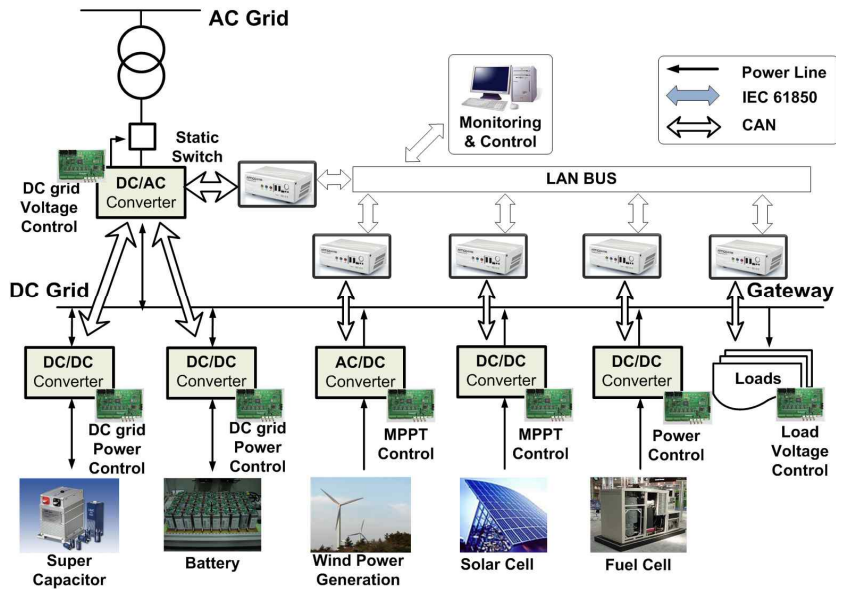

Fig. 1. DC Micro-grid Configuration

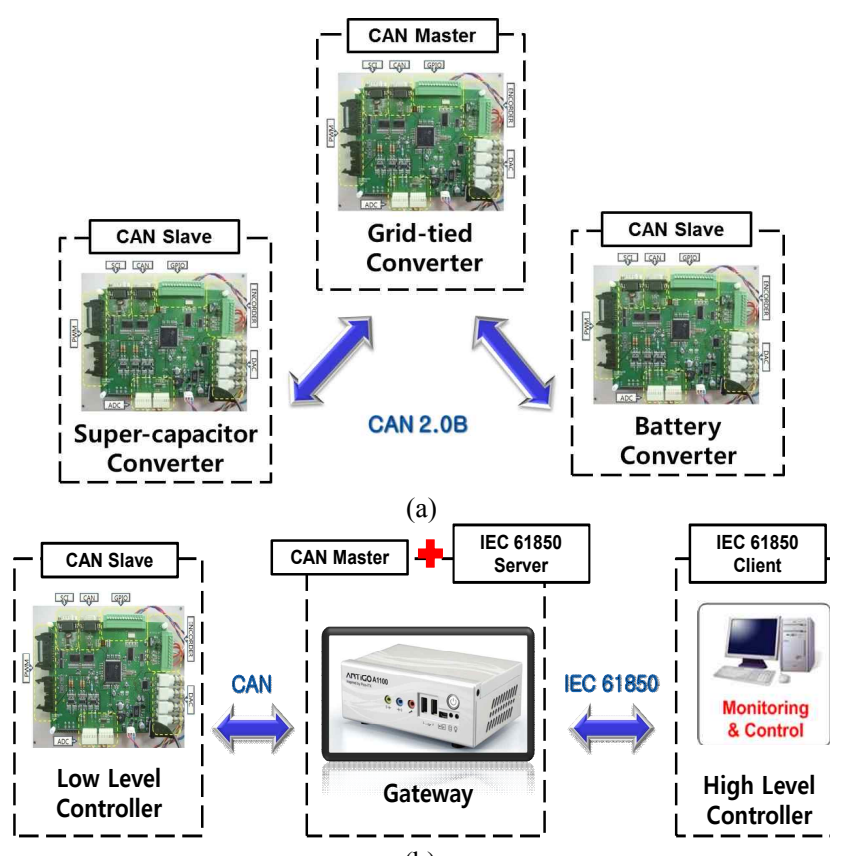

(b)

Fig. 2. Two types of Communication Link (a) Small-scale CAN (b) CCP-to-IEC61850.

like a CCP master and a IEC61850 server. The converted IEC 61850 data at the gateway is transmitted to the main controller which works like a client. The CCP enables collecting and modifying the data for each variable through easy access to the memory address of the CCP library. This remarkable advantage shows that the $\mathrm{CCP}$ can be utilized for the communication link in a DC micro-grid.

\section{DC MICRO-GRID OPERATION}

\section{A. Power Management Method}

The power management method is analyzed in both the gridtied mode and islanded mode. The grid-tied converter has control of the DC grid voltage in the grid-tied mode, while one of the energy storage elements has this control in the islanded 
mode. Super-capacitors and batteries ensure high a quality power supply to the load in both modes. Although batteries with a fast response and good characteristics such as li-ion batteries are receiving a great deal of attention these days, they are still very expensive. The sum cost of a low capacity supercapacitor and an inexpensive battery is cheaper than the cost of using a battery that shows high performance even including the number of converters.

Fig. 3(a) illustrates the concept of a power management method in the grid-tied mode, and the bolded curve represents a load demand curve during one day. If output sum of the distributed sources is sufficient to charge the storage elements, excessive power is supplied to the ac grid. If power sum of the distributed sources and storage elements is deficient in terms of the load demand, lack of power is supplied from the ac grid. In the grid-tied mode, power management is performed in a complementary manner between storage elements and then a DC micro-grid can operate safely and efficiently.

In the islanded mode, power management is not secured by a super-capacitor because its energy storage capacity is too limited to cover long-term power supply requirements. However, it has fast charging and discharging capability. When compared with a super-capacitor, a battery shows a relatively low response but meets the requirements of longterm power supply. Therefore, the super-capacitor undertakes sudden and small power changes while the battery undertakes the demand of huge power for long periods of time. In other words, the super-capacitor is operative at the moment of transition from charge mode to discharge mode or vice verse. If the super-capacitor reaches its full capacity, the supercapacitor converter stops and then the battery converter takes over the charge/discharge operation, i.e. power management. Fig. 3(b) illustrates the concept of a power management method in the islanded mode. When a DC micro-grid must be separated from the ac grid and a move to the islanded mode is acknowledged, the grid-tied converter released a control about the DC grid. Since each converter of the distributed sources is used for optimal control of each source, only the converters of energy storage elements can afford to regulate the DC grid voltage. During the islanded mode, batteries play a main role in regulating the DC grid voltage while super-capacitors play a secondary role in responding to sudden power requirements as an auxiliary converter. In other words, the super-capacitor regulates the DC grid voltage at the moment of charging discharging transition and makes up lacks of power which the battery cannot handle. Therefore, the power capability of super-capacitors can be reduced significantly in the islanded mode.

\section{B. Control of the Energy Storage Element}

Fig. 4(a) shows a control method for energy storage elements during the grid-tied mode. Energy storage elements
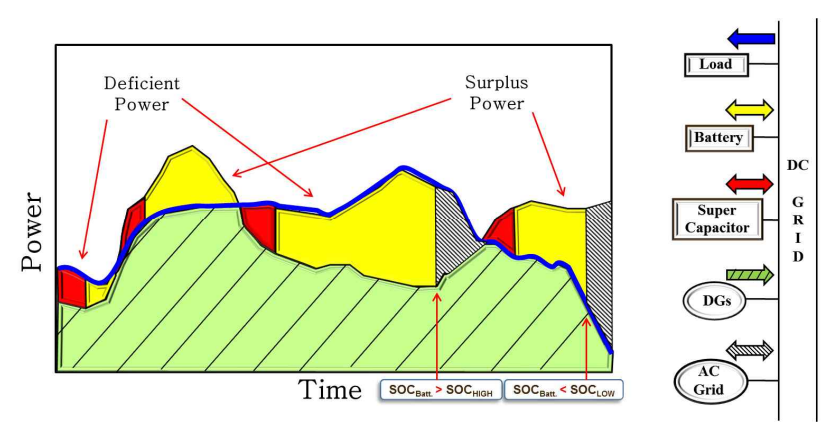

(a)
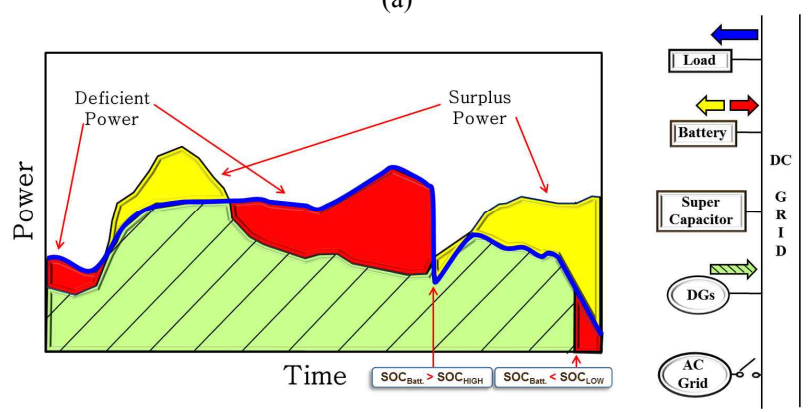

(b)

Fig. 3. Energy management concept (a) Grid-tied mode (b) Islanded mode.

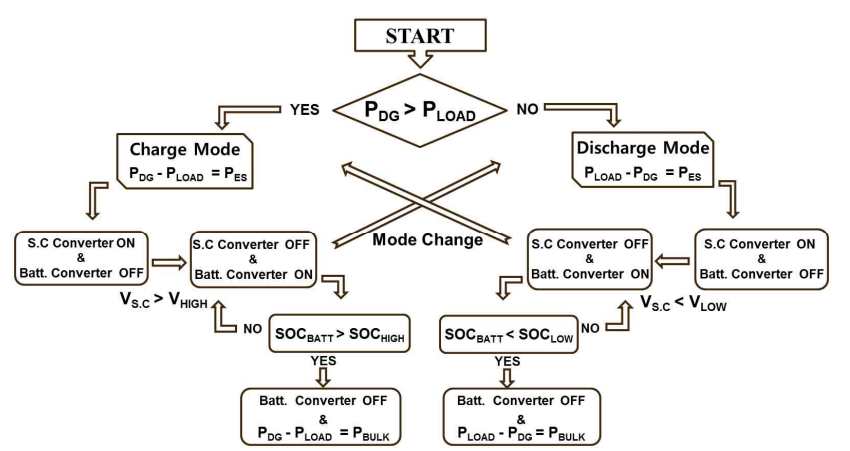

(a)

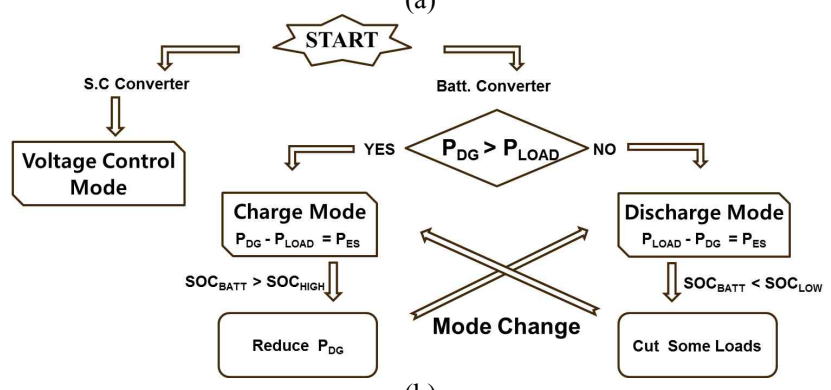

(b)

Fig. 4. Power Management Logic (a) Grid-tied operation (b) Islanded operation.

can transfer between charge and discharge modes in order to maintain the DC grid power balance. If the energy storage elements reach their capacity limitation, it keeps the DC grid power balanced by exchanging a power from the $\mathrm{AC}$ grid. $\mathrm{P}_{\mathrm{DG}}$ is defined as total sum of the output from the distributed sources and the energy storage elements while charging discharging a difference between $\mathrm{P}_{\mathrm{DG}}$ and $\mathrm{P}_{\mathrm{LOAD}}$. 


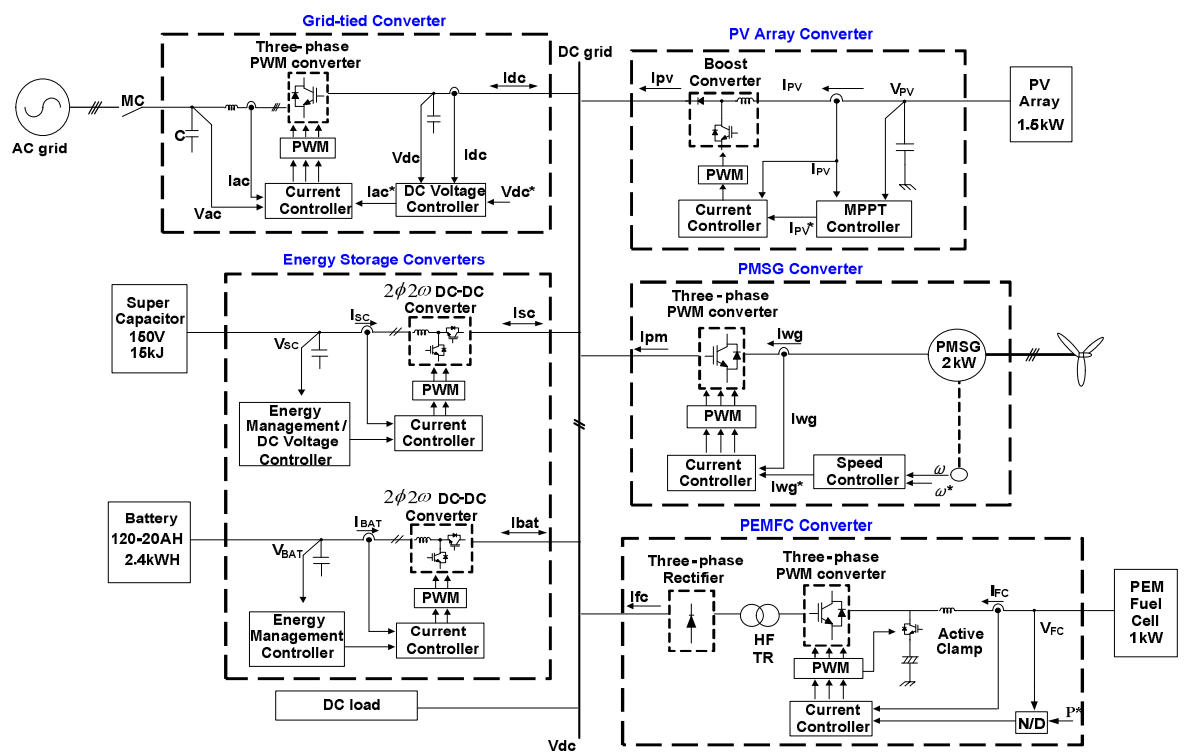

Fig. 5. Component Control of DC micro-grid.

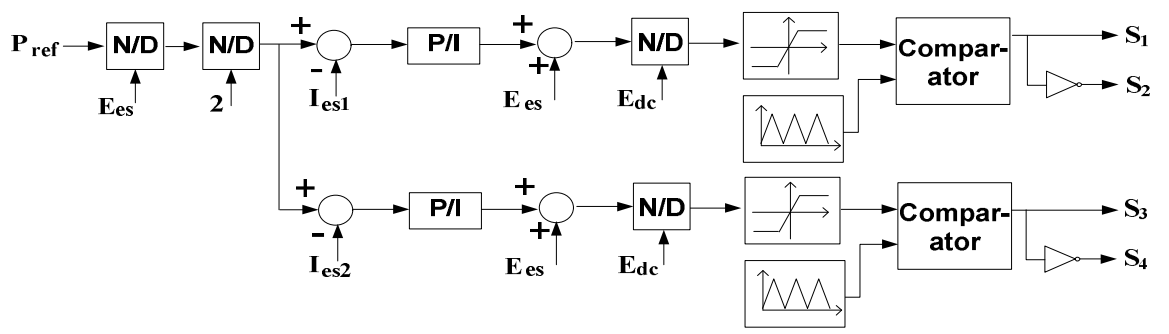

(a)

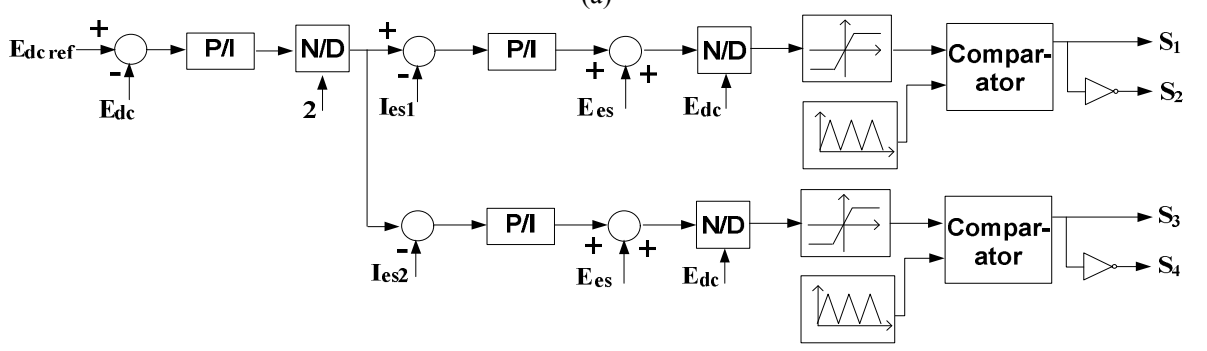

(b)

Fig. 6. DC-DC Converter Control for Energy Storage (a) Grid-tied operation (b) Islanded operation.

If $\mathrm{P}_{\mathrm{DG}}$ is larger than $\mathrm{P}_{\mathrm{LOAD}}$, the difference is charged to the storage elements. In the beginning of the charging interval, the super-capacitor converter starts to charge and if the supercapacitor voltage reaches its maximum voltage set-value, the converter stops charging. Then the battery converter takes over control of the power management and starts to charge the difference. When the battery is completely charged, the battery converter stops charging, and the surplus power generated from this moment is transferred to the AC grid.

If $\mathrm{P}_{\mathrm{DG}}$ is smaller than $\mathrm{P}_{\mathrm{LOAD}}$, the discharge interval starts, and the difference is discharged from the storage elements. As with the charging interval, the super-capacitor converter starts to discharge first, and it stops discharging when the supercapacitor voltage reaches its minimum voltage set-value. After that, the battery converter start to discharge and the converter stops when the battery is discharged completely. Deficient power demanded from this moment is supplied by the AC grid.

Fig. 4(b) shows a control method for energy storage elements during islanded mode. During the islanded mode, both the super-capacitor and battery converters operate continuously. The super-capacitor keeps the DC grid voltage constant even under an abrupt power changes as an auxiliary element, and the battery performs power management as a main element.

The battery converter operates with an algorithm that is similar to the one used in the grid-tied mode. If the battery is charged up to its maximum soc set-value, the outputs of distributed sources are limited and clamped to the load demand. If the battery discharges down to its minimum soc set-value, an uncritical load is disconnected from the DC 
micro-grid so that the available output of the distributed sources can keep supplying power to the critical loads.

\section{Control of a DC Micro-grid}

Fig. 5 shows a control block diagram of the components in the proposed DC micro-grid.

The grid-tied three-phase converter maintains the dc-grid voltage by an outer voltage loop and an inner current loop. The photovoltaic converter operates on the maximum power point which is a nonlinear function of the irradiation and temperature. The Perturbation \& Observation technique is employed for the MPPT method since it is stable and easily implemented. The wind power generation also runs with the MPPT method, where maximum power is achieved by keeping the power coefficient of the blade at its maximum value regardless of varying wind-speeds. The wind power converter controller consists of an outer speed loop and an inner current loop. Since the output voltage of fuel cells has a $1: 2$ of variation between the rated-load and the no-load, the fuel cells converter needs a high voltage step-up capability. The fuel cell converter controller consists of a current controller and a current command generator, which calculates the reference current by dividing the power command by the fuel cell output voltage.

Fig. 6(a) shows a control block diagram of the battery and super capacitor converters during grid-tied mode. The reference power is the difference between the total power generated from the distributed sources and the load demand.

The reference current is calculated by dividing the reference power by the output voltage of the storage element. Then the reference current for each converter leg is calculated by halving the reference current. Each of the PI controllers process errors between the reference current and the feedback current of each leg. Then they generate PWM gate pulses through a comparator. Fig. 6(b) shows a control block diagram of the super capacitor converter during islanded mode.

The outer voltage controller calculates the reference current by processing the errors between the reference voltage and the feedback dc-grid voltage. The same structure is then used for the inner current controller.

\section{INTEGRATED OPERATION TEST}

The operation of the DC micro-grid was analyzed using the detail simulation model with PSCAD/EMTDC software described in [13]. Based on the simulation results, a hardware simulator for the DC micro-grid was built with commercially available components. Fig. 7 shows the whole system configuration of the DC micro-grid hardware simulator for the integrated operation test. The hardware simulator consists of a fuel-cell generator, a PV power simulator, the DC micro-grid assembly, a wind power simulator, a Ni-MH battery stack, a PC (personal computer) for the main controller and a variable DC load. The experimental data of the integrated operation test are displayed on a 16-channel oscilloscope.

The detailed structure of the DC micro-grid assembly is shown in Fig. 8. There are five sub-assemblies of the

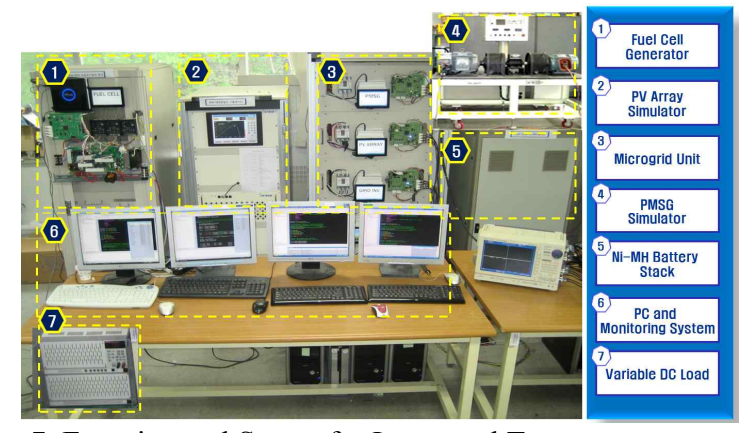

Fig. 7. Experimental Set-up for Integrated Test.

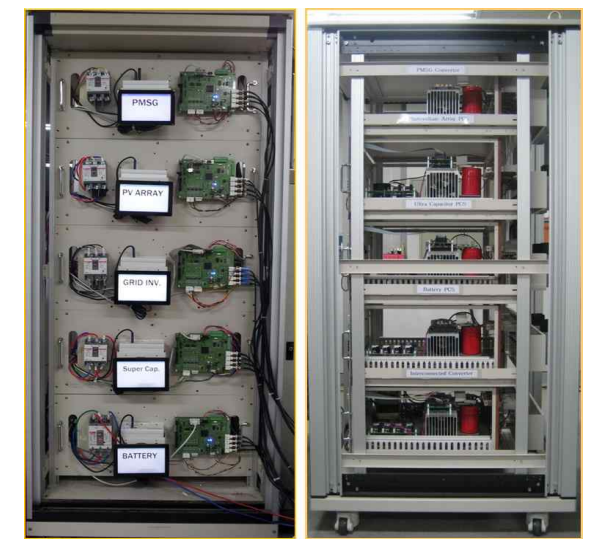

Fig. 8. Structure of DC Micro-grid Assembly.

converters in the DC micro-grid assembly. They are made up of three DC-DC converters for PV power generation, batteries and super-capacitors, two DC-AC converters for wind power generation and $\mathrm{AC}$ grid connections. Each converter subassembly is mounted on a small iron drawer. One DC-DC converter sub-assembly is separately mounted on the front side of the fuel-cell generator. The super-capacitor was mounted inside one of the DC-DC converter drawers. The local controllers and gateway devices are mounted on the front side of the DC-micro-grid assembly with small displays for checking the transmitted data. On the back side of the DC micro-grid assembly a DC bus is installed, which is connected to all of the output terminals of the DC-DC and DC-AC converters.

Table I shows the major items to be checked in the experimental study. The experiments were carried out based on the simulation results. First the communication speed in the small-scale CAN link and CCP-to-IEC61850 link was checked. Transient phenomena due to step changes of the command signal were checked, and high-speed sequence changes due to main control logic were also checked. Transient phenomena due to operation mode changes or step load changes were checked too.

\section{A. Communication Operation}

Fig. 9 shows the communication link in the DC micro-grid for data transmission and receiving. Operation and control commands are transmitted to the small-scale CAN link, and 
TABLE I

CHECKING ITEMS IN EXPERIMENT

\begin{tabular}{|c|c|}
\hline No. & Checking Item \\
\hline 1 & $\begin{array}{c}\text { Communication Speed between Main controller and } \\
\text { Local Controller }\end{array}$ \\
\hline 2 & $\begin{array}{c}\text { Transient in Mode Change from Charging to } \\
\text { Discharging }\end{array}$ \\
\hline 3 & Sequence Change with Algorithm \\
\hline 4 & DC Bus Voltage and Transient in Energy Storage \\
\hline 5 & Stable Power Supply to DC Load \\
\hline 6 & Transient due to Operation Mode Change \\
\hline
\end{tabular}

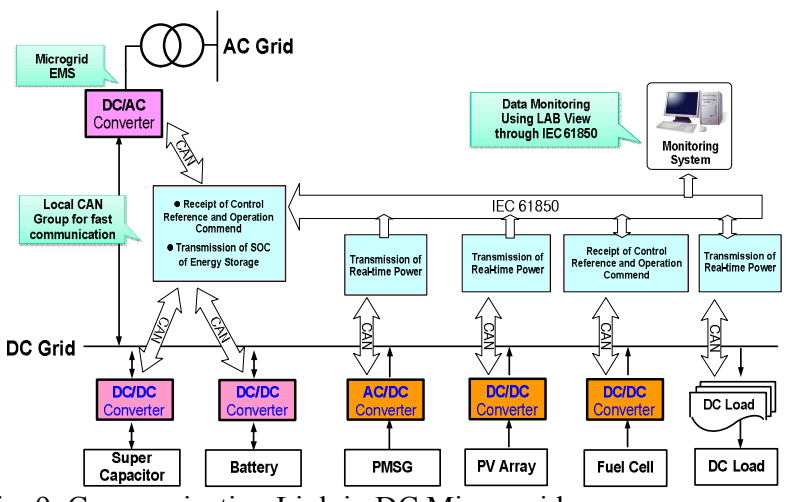

Fig. 9. Communication Link in DC Micro-grid.

the monitoring of data for checking the charging state are transmitted to the main controller through the CCP-toIEC61850 link. The local controllers for the wind power and PV power sources transmit their output power to the main controller through the gateway. The control command for the fuel-cell power source is transmitted to the local controller from the main controller through the gateway.

Fig. 10 shows the test results of the data communication in the small-scale CAN link and the CCP-to-IEC61850 link. Fig. 10(a) shows the test results of the data communication in the small-scale CAN link between the local controller of the energy storage converter and the grid-tied converter. In the small-scale CAN, data with an 8-byte maximum length can be transmitted or received 7 times during $1 \mathrm{~ms}$. As a result, the transmission speed is 143us which is enough for real-time operation. Fig. 10(b) shows the test results of the data communication in the CCP-to-IEC61850 link between the local controller of the grid-tied converter and the fuel-cell converter through the gateway. The turn-around time between the two local controllers is about $120 \mathrm{~ms}$, which is enough time for implementing real-time energy management.

\section{B. Grid-tied Operation}

To confirm the checking items on Table I, the experiment has been carried out with reasonable scenarios. The output of the sum of the distributed generations is changed intentionally to check the transient response in the DC micro-grid. Table II shows the pointer of the state transition on the measured graph in Fig. 11.

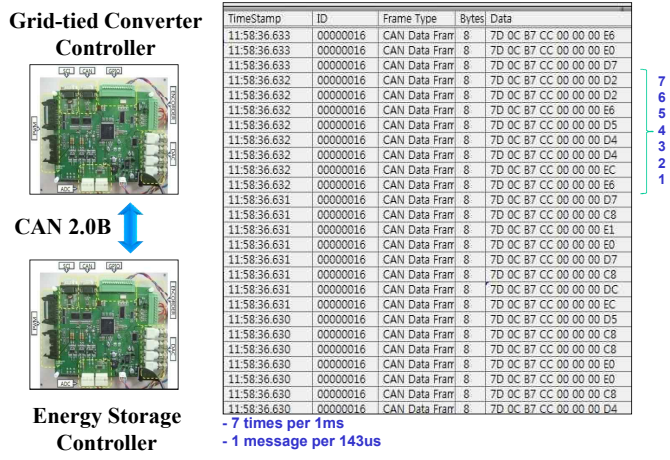

(a)

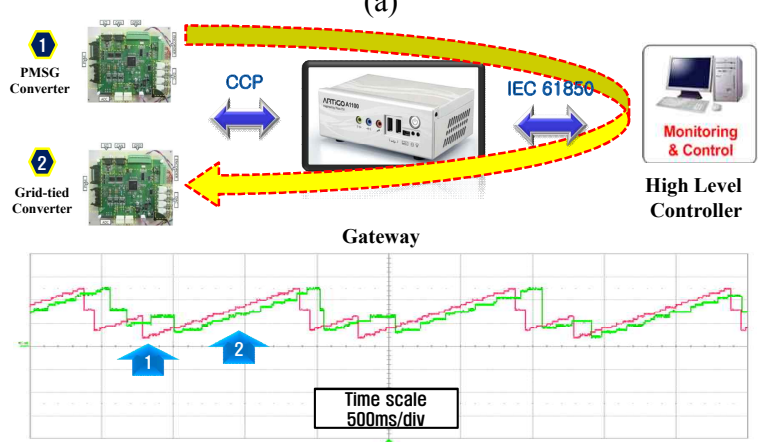

(b)

Fig. 10. Data Communication Test Results (a) Small-scale CAN Link Test (b) CCP-to-IEC61850 Link Test.

TABLE II

State Transition Pointer in Figure 11

\begin{tabular}{|c|c|c|c|c|}
\hline Pointer & Fig. 11 (a) & Fig. 11 (b) & Fig. 11 (c) & Fig. $11(\mathrm{~d})$ \\
\hline No.1 & Start DGs & Start ESS & $\begin{array}{c}\text { Start } \\
\text { Charging }\end{array}$ & $\begin{array}{c}\text { Start } \\
\text { Charging }\end{array}$ \\
\hline No.2 & $\begin{array}{l}\text { FC output } \\
\text { Change }\end{array}$ & $\begin{array}{c}\text { Transfer } \\
\text { Power to AC } \\
\text { Network }\end{array}$ & $\begin{array}{c}\text { Stop } \\
\text { Charging }\end{array}$ & $\begin{array}{c}\text { Stop } \\
\text { Charging }\end{array}$ \\
\hline No.3 & $\begin{array}{l}\text { PMSG } \\
\text { output } \\
\text { Change }\end{array}$ & $\begin{array}{l}\text { Mode change } \\
\text { from Charge to } \\
\text { Discharge }\end{array}$ & $\begin{array}{c}\text { Start } \\
\text { Discharging }\end{array}$ & $\begin{array}{c}\text { Start } \\
\text { Discharging }\end{array}$ \\
\hline No.4 & $\begin{array}{l}\text { PV Array } \\
\text { output } \\
\text { Change }\end{array}$ & $\begin{array}{l}\text { Supplied from } \\
\text { AC Network }\end{array}$ & $\begin{array}{c}\text { Stop to } \\
\text { Discharging }\end{array}$ & $\begin{array}{c}\text { Stop to } \\
\text { Discharging }\end{array}$ \\
\hline
\end{tabular}

Fig. 11 shows the experimental results when the DC microgrid is interconnected with the AC network. Fig. 11(a) shows the output power of a PMSG wind generator, a PV generator, and a fuel-cell generator, plus the total output power of all of the distributed power sources. The output power is changed according to the step change command. Fig. 11(b) shows the power to the AC network, the total output power of the distributed sources, the load consumed power, and the DC grid voltage. When the battery reaches its high or low limit, the required power in load is supplied from or transferred to the AC network. During the whole operation, the consumed power in the load is supplied properly and the DC grid voltage is maintained at a constant value. Fig. 11(c), (d) show the dynamic characteristics of the super-capacitor and battery. The charge and discharge actions occurs properly according to the command from the main controller. Fig. 11(e) shows the performance of the dynamic response when the small-scale CAN works to control power in the energy storage. 


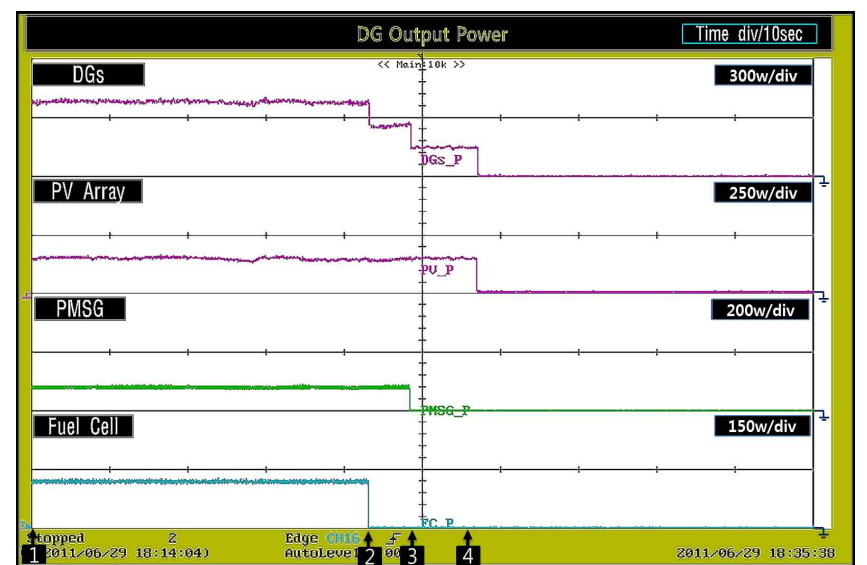

(a)

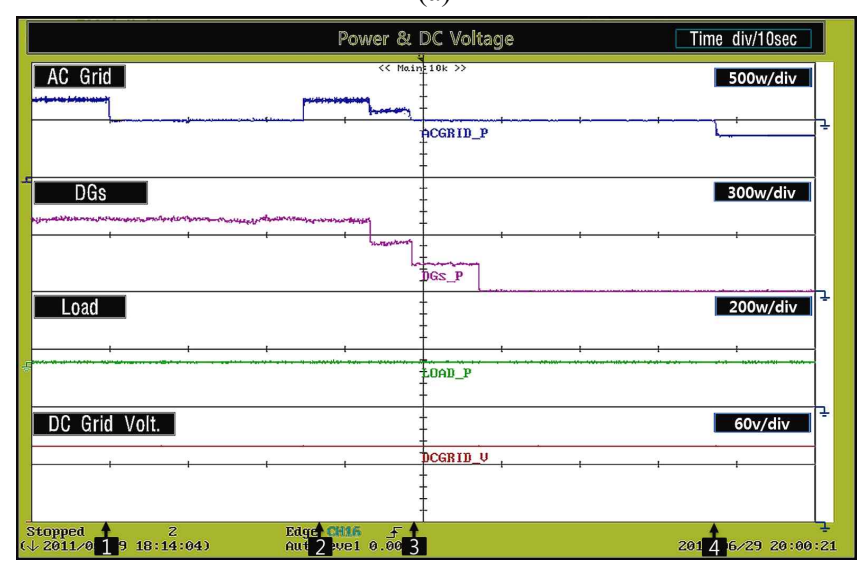

(b)

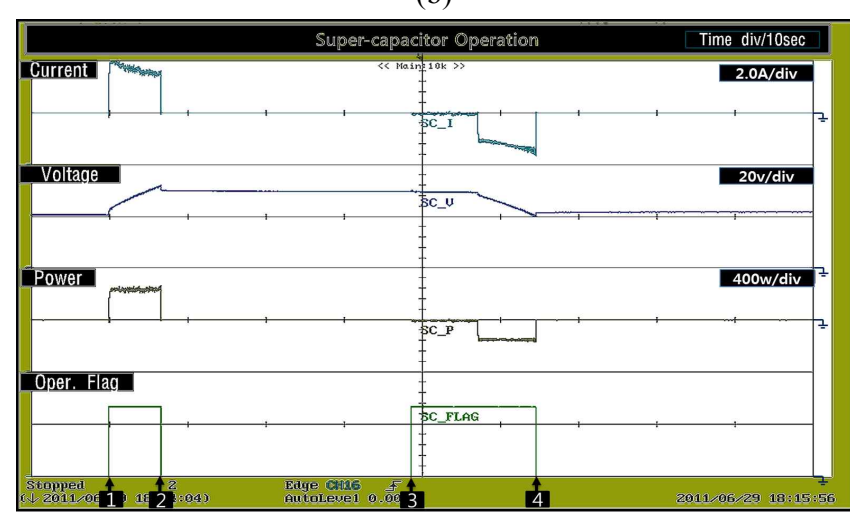

(c)

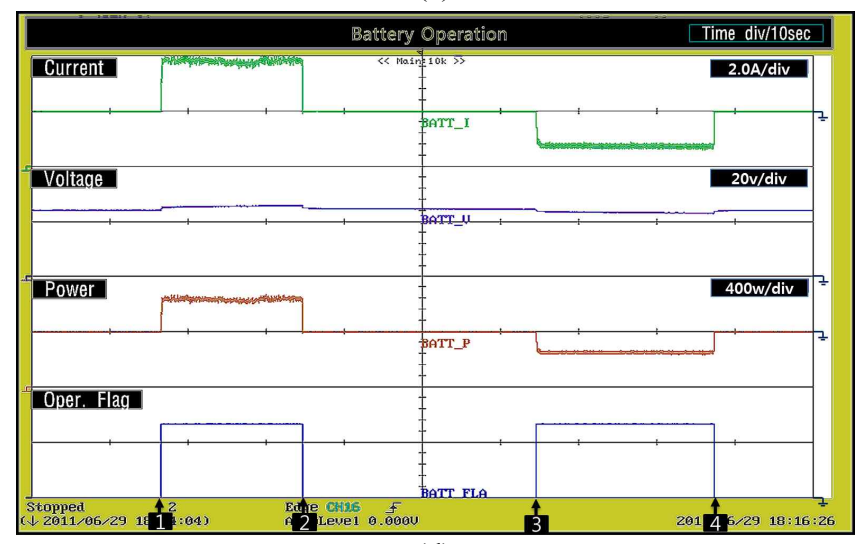

(d)

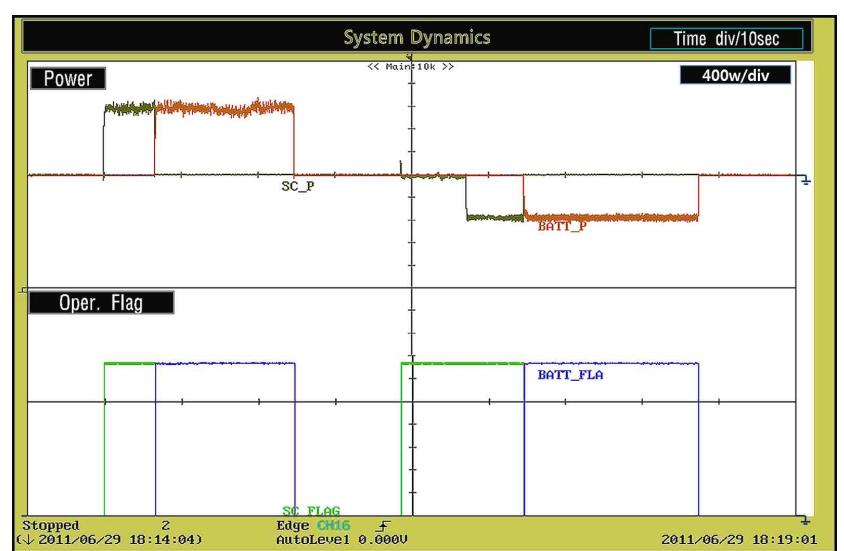

(e)

Fig. 11. Experimental Results in Grid-tied Operation (a) Output Power in Distributed Power Source (b) Power Management (c) Super-capacitor Response (d) Battery Response (e) Dynamic Response in Energy Storage.
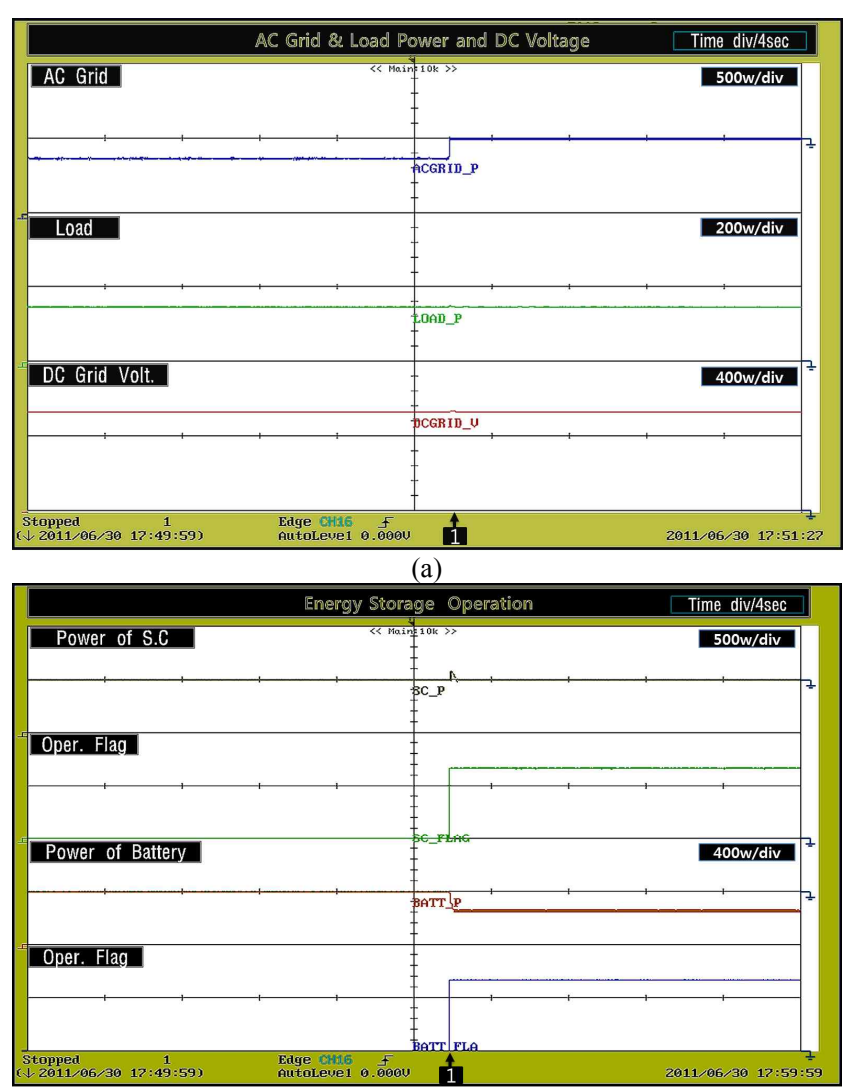

(b)

Fig. 12. Dynamic Response due to Mode Change (a) Power Transient Response (b) Super-capacitor Response.

\section{Islanding Operation}

Fig. 12 shows the experimental results when the DC microgrid has a mode change from grid-tied to islanded operation. Pointer No.1 indicates the state transition from the grid-tied mode to the islanding mode. Fig. 12(a) shows the deficient power transferred from the ac grid during mode change. At the instance of islanding, the DC grid voltage is maintained at a constant value without transients. 
TABLE III

State Transition In Figure 13

\begin{tabular}{|c|c|c|c|}
\hline Pointer & Fig. 13 (a) & Fig. 13 (b) & Fig. 13 (c) \\
\hline No.1 & $\begin{array}{c}\text { Increase DG } \\
\text { output }\end{array}$ & $\begin{array}{c}\text { Compensate } \\
\text { Deficient Power }\end{array}$ & $\begin{array}{c}\text { Change to } \\
\text { Charging Mode }\end{array}$ \\
\hline No.2 & $\begin{array}{c}\text { Decrease } \\
\text { DG output }\end{array}$ & $\begin{array}{c}\text { Compensate } \\
\text { Deficient Power }\end{array}$ & $\begin{array}{c}\text { Battery reach } \\
\text { its limit }\end{array}$ \\
\hline
\end{tabular}

As a result, the power is supplied to the load in a stable manner. Fig. 12(b) shows the experimental results of the super-capacitor and battery responses at the instant of mode change. The super-capacitor maintains the DC grid voltage while the battery performs power management.

Fig. 13 shows the experimental results when the DC microgrid is disconnected from the AC network. Table III shows the pointer of the state transition on the measured graph in Fig. 12.

Fig. 13(a) shows the total output power of all of the distributed power sources, the load consumed power, and the DC grid voltage. When the battery reaches its high limit, the output power of the fuel cell is controlled as zero. Therefore, the total output power of all of the distributed power sources is reduced. During the whole operation, the consumed power in load is supplied properly and the DC grid voltage is maintained at a constant value.

Fig. 13(b), (c) show the dynamic characteristics of the super-capacitor and battery. When islanding occurs, the supercapacitor controls the dc-grid voltage and makes up the lack of power which the battery cannot handle, and the battery converter controls the power as much as the difference between the sum of DGs output power and the load power. The load consumes constant power and the sum of the DGs output power is changed. As a result, the battery increase or decrease its power to match the balance of power at the dc grid and the waveform of the battery power is similar to that of the DGs power.

\section{CONCLUSION}

This paper describes the operation analysis results of a communication-based DC micro-grid using a hardware simulator developed in the lab. The developed hardware simulator is composed of distributed generation devices such as wind power, photovoltaic power and fuel cells; and energy storage devices such as super-capacitors and batteries. Whole system monitoring and control was implemented using a personal computer. The power management scheme was implemented in the main controller based on a TMS320F28335 chip.

The main controller is connected with the local controller in each of the distributed generation and energy storage devices through a communication link based on a CAN or IEC61850. A CAN was used for the data communication between the grid-tied converter and the energy storage converter. An IEC61850 was used for the data communication between the

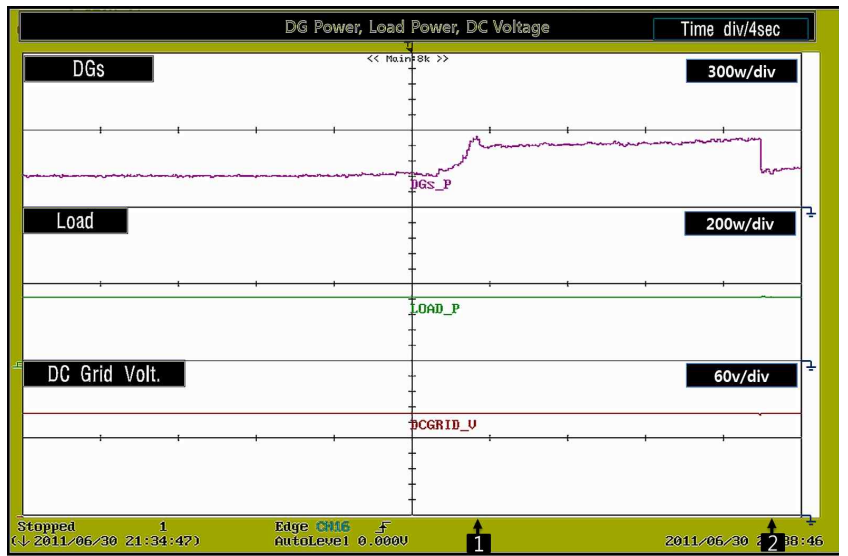

(a)

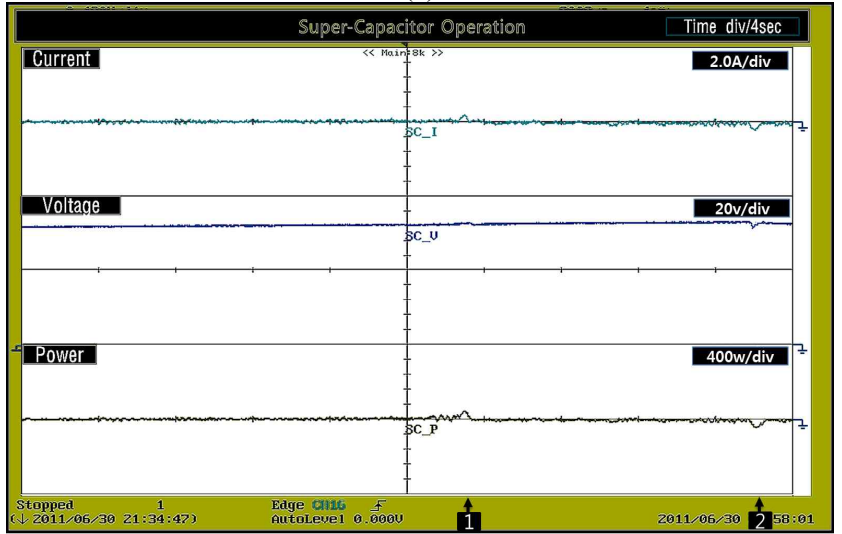

(b)

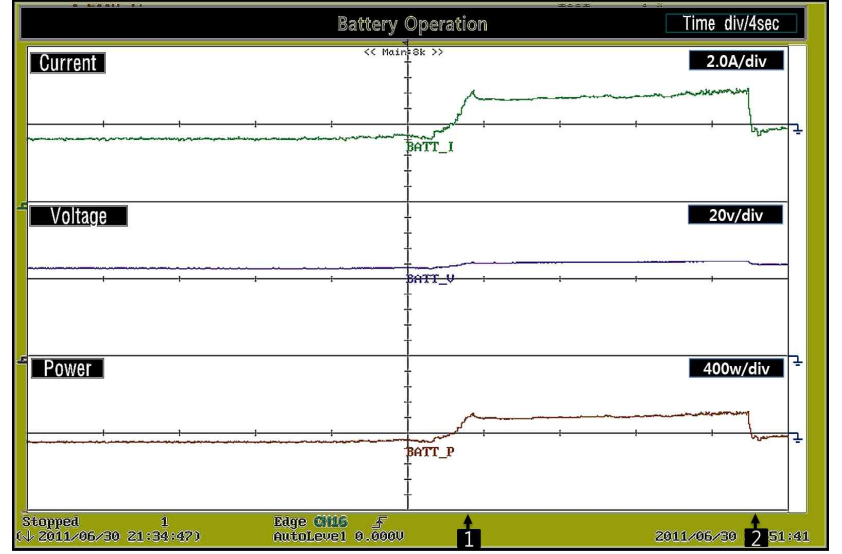

(c)

Fig. 13. Experiment result in Islanded Operation (a) Power Management (b) Super-capacitor Response (c) Battery Response.

main controller and the local controllers for the grid-tied converter and for all of the DG converters.

The operation analysis results using the developed hardware simulator confirm the ability of the DC micro-grid to supply electric power to end users. The developed hardware simulator can operate with high reliability through a high-speed communication link. It can operate stably without being influenced by adding more DGs or loads. The developed hardware simulator can be utilized in designing an actualrating DC micro-grid in a practical manner. 


\section{ACKNOWLEDGMENT}

This work was supported by the Human Resources Development and Power Generation \& Electricity Delivery of the Korea Institute of Energy Technology Evaluation and Planning (KETEP) grant funded by the Korea Ministry of Knowledge Economy. (No. 20114010203030 \& 20111020400080)

\section{REFERENCES}

[1] F. Katiraei and M. R. Iravani, "Power management strategies for a microgrid with multiple distributed generation units," IEEE Trans. Power Systems, Vol. 21, No. 4, pp. 1821-1831, Nov. 2006.

[2] H. Nikkhajoei and R. H. Lasseter, "Distributed generation interface to the certs microgrid," IEEE Trans. Power Del., Vol. 24, No. 3, pp. 1598-1608, Jul. 2009.

[3] B. Wang, M. Sechilariu, and F. Locment, "Intelligent DC microgrid with smart grid communications: control strategy consideration," IEEE Trans. Smart Grid, Vol. 3, No. 4, pp. 2148-2156, Dec. 2012.

[4] H. Kakigano, Y. Miura, T. Ise, and chida, "C micro-grid for super high quality distribution -system configuration and control of distributed generation and energy storage devices,'IEEE PESC'06, Jun. 2006.

[5] P. Biczel, "Power electronic converters in dc microgrid," IEEE CPE'07, May 2007.

[6] F. Katiraei, R. Iravani, and P. Lehn, "Micro-grid autonomous operation during and subsequent to islanding process," IEEE Trans. Power Del., Vol. 20, No. 1, pp. 248-527, Jan. 2005.

[7] P. Piagi and R. H. Lasseter, "Autonomous control of microgrids," IEEE PES General Meeting, Oct. 2006.

[8] D. Chen and L. Xu, "Autonomous de voltage control of a dc microgrid with multiple slack terminals," IEEE Trans. Power Syst., Vol. 27, No. 4, pp. 1897-1905, Nov. 2012.

[9] Y. Ito, Y. Zhongqing, and H. Akagi, "DC microgrid based distribution power generation system," IEEE Power Electronics and Motion Control Conference, Vol. 3, pp. 1740-1745, Aug. 2004.

[10] Y. Zhu, F. Zhuo, and L. Xiong, "Communication platform for energy management system in a master-slave control structure microgrid," IEEE 7th International Power Electronics and Motion Control Conference, Vol. 1, pp. 141145, Jun. 2012.

[11] R. Bi, M. Ding, and T. T. Xu, "Design of common communication platform of microgrid," IEEE Power Electronics for Distributed Generation Systems, Jun. 2010.

[12] A. Ruiz-Alvarez, A. Colet-Subirachs, O. Gomis-Bellmunt, J. M. Fernàndez -Mola, J. López-Mestre, A. Sudria -Andreu, "Design, management and comissioning of a utility connected microgrid based on IEC 61850," IEEE PES ISGT Europe, Oct. 2010.

[13] J.-H. Lee, H.-J. Kim, B.-M. Han, Y.-S. Jeong, H.-S. Yang and H.-J. Cha, "DC micro-grid operational analysis with a detailed simulation model for distributed generations," Journal of Power Electronics, Vol. 11, No. 3, pp. 350-359, May 2011.

[14] J.-H. Jeon, J.-Y. Kim, H.-M. Kim, S.-K. Kim, C. Cho, J.-M Kim, J.-B. Ahn, and K.-Y. Nam, "Development of hardware in-the-loop simulation system for testing operation and

control functions of microgrid," IEEE Trans. Power Electron., Vol. 25, No. 12, pp. 2919-2929, Dec. 2010.

[15] J. Lee, B. Han, and H. Cha, "Development of Hardware Simulator for DC Micro-grid Operational Analysis" IEEE PES General Meeting, Jul. 2012.

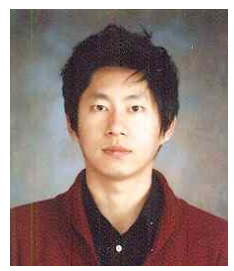

Ji-Heon Lee received his B.S. and M.S. in Electrical Engineering from Myongji University, Seoul, Korea, in 2008 and 2010, respectively. He is currently a Ph.D. candidate at Myongji University. His current research interests include power electronics applications for distributed generation and micro-grids.

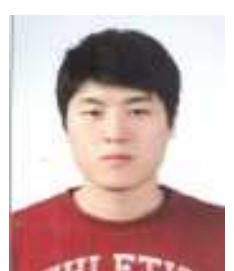

micro-grids.
Hyun-Jun Kim received his B.S. and M.S. in Electrical Engineering from Myongji University, Seoul, Korea, in 2011 and 2013, respectively. He is currently persuing his Ph.D. at Myongji University. His current research interests include power electronics applications for distributed generation and

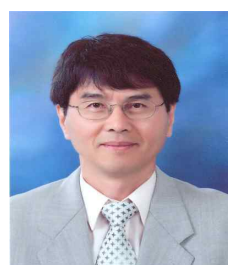

Byung-Moon Han received his B.S. in Electrical Engineering from Seoul National University, Seoul, Korea, in 1976, and his M.S. and Ph.D. from Arizona State University, USA, in 1988 and 1992, respectively. He was with the Westinghouse Electric Corporation as a Senior Research Engineer in the Science and Technology Center, Pittsburg, PA, USA. He is currently a Professor in the Department of Electrical Engineering, Myongji University, Seoul, Korea. His current research interests include power electronics applications for FACTS, custom power, and distributed generation. 